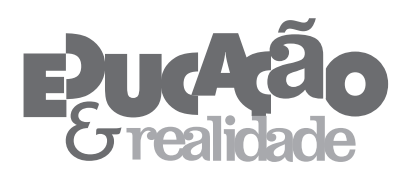

\title{
Avances en la Normativa del Derecho a la Educación en Cárceles de la Argentina
}

Francisco Scarfó

Florencia Pérez Lalli

Ivana Montserrat

RESUMEN - Avances en la Normativa del Derecho a la Educación en Cárceles de la Argentina. Se reconoce que en las últimas décadas ha habido un cierto progreso en el establecimiento de garantías para el respeto de los derechos humanos en general y, en particular, el derecho a la educación pública para jóvenes y adultos en situación de encarcelamiento. Por otra parte, también se reconoce que hay dificultades todavía muchos a su pleno ejercicio. Con el objetivo de discutir más a fondo el tema, el artículo reflexionará sobre el derecho a la educación en las cárceles y de los avances históricos de la aplicación del derecho penal en la Argentina.

Palabras-clave: Educación en las Prisiones. El Derecho a la Educación. La Política de Ejecución Penal.

ABSTRACT - Advances in the Laws of Educational Rights in Prisons of Argentina. It is acknowledged that in recent decades some progress was achieved in establishing guarantees for the respect of Human Rights as a whole, and particularly the right to public school education for the youth and also for the adults who are in prison. On the other hand, it is also acknowledged that there still are many difficulties for its full functioning. This article - with the objective of deepen the discussion on the topic - will reflect on the right to education in prison and on the historical progress of criminal enforcement laws in Argentina.

Keywords: Education in Prison. Right to Education. Criminal Enforcement Policy. 
Se reconoce que en las dos últimas décadas hubo ciertos avances en cuanto al establecimiento de garantías para el respeto de los Derechos Humanos en general, y del Derecho a la Educación Pública en contextos de encarcelamiento, en particular. Sin embargo se conoce también que aún existen muchas dificultades para su pleno ejercicio.

Se entiende que la educación pública en cárceles se constituye como el deber del Estado en respetar, proteger, garantizar, promover y facilitar el acceso y el disfrute con calidad de la educación básica y media en función de ser componentes del Derecho a la Educación, plasmado en los distintos instrumentos internacionales de Derechos Humanos y recientemente manifestado en la Ley Nacional de Educación- 26.206 del año 2006- en su Capitulo XII: "Educación en Contextos de Privación de Libertad" (artículos 55 al 59) ${ }^{1}$

Esto implica que la educación pública en las cárceles, debe ser entendida como el ejercicio de un derecho humano que no apunte al tratamiento penitenciario, sino al desarrollo integral de la persona; a mejorar su calidad de vida, formarse profesionalmente, acceder y disfrutar de la cultura, en resumen, a la posibilidad de realizar trayectorias educativas provechosas que permitan construir un proyecto de vida, ya sea durante o después de la cárcel.

En los últimos años, se ha dado una tendencia favorable a garantizar este derecho. Se puede observar como auspiciosa la presencia de escuelas públicas primarias de adultos en la gran mayoría de las Unidades Penales - ya sea en el ámbito penitenciario federal y provincial-, la extensión de escuelas medias, la diversificación y ampliación de los turnos en la oferta educativa, la ampliación de espacios físicos para el estudio, y la incorporación del dictado de clases por parte de docentes de nivel educativo público oficial.

Otro aspecto a resaltar es que la educación en la mayoría de las jurisdicciones del país es gestionada por los Ministerios Públicos de Educación, recomendación que está contenida en toda la normativa internacional referida a la ejecución de la pena, en especial en las Reglas Mínimas para el Tratamiento de los Reclusos de Naciones Unidas ${ }^{2}$. Como muestra de esta tendencia, se destaca parte de la Recomendación $N^{o} R$ (89) 12 del Comité de Ministros de los Estados Miembros sobre Educación en Prisiones ${ }^{3}$,

[...] Teniendo consideración hacia la Recomendación No. R (87) 3 sobre Normas Penitenciarias Europeas y a la Recomendación $N^{o}$. R (81) 17 sobre política de la educación de adultos, recomienda a los gobiernos de los estados miembros implementar políticas que reconozcan lo siguiente: 1. Todas las personas internas en prisión tendrán acceso a la educación, que comprende las disciplinas escolares, formación profesional, actividades culturales y creativas, educación física y deportes, educación social y servicios de biblioteca; 
2. La educación de estas personas debe ser la misma que la que se proporciona a similares grupos de edad en el exterior, y la gama de oportunidades de aprendizaje debe ser lo más amplia posible;

3. La educación en prisión se orientará al desarrollo integral de la persona, teniendo en cuenta su contexto social, económico y cultural;

4. Deben proporcionarse programas de desarrollo para asegurar que los educadores penitenciarios adoptan los métodos apropiados de educación de adultos;

5. Se debe disponer de fondos, equipamiento y personal docente necesario para que los internos reciban una educación apropiada.

Sin embargo, aún perduran varias dificultades. Una de ellas es que muchos/as funcionarios/as del Estado, conciben limitadamente a la educación como la ocupación del tiempo libre y como herramienta de 'reinsersión social', reduciendo así las posibilidades reales del ejercicio de la educación como un derecho.

En este sentido, se corre el riesgo de concebir la educación como un dispositivo que facilite su ejercicio como privilegio o bien de intercambio - en función de la buena o mala conducta - o sometido al acceso a otros derechos, reduciendo así las posibilidades reales del ejercicio de la educación como un derecho en sí mismo inherente a la dignidad humana. Situación que, a su vez, conlleva implícitamente una práctica 'paternalista' por parte de la gestión penitenciaria y/o de los/as funcionarios/as del sistema educativo.

Las cuestiones de seguridad en el ámbito de la cárcel también suelen ser una limitación a la práctica de este derecho como de otros tantos, cuando son instrumentadas de manera abusiva y sin justificación legal. Esto implica una restricción en el acceso masivo a la educación afectando a los grupos de presos/as considerados en situación de alta vulnerabilidad (los/as sancionados/as, los/as de orientación sexual diversa, los/ as que sufren alguna discapacidad física y mental, los/as enfermos/as, los/as que se encuentran bajo tratamiento de droga dependencia, entre otros).

Concretamente existen muchas restricciones de diverso origen en el disfrute del Derecho a la Educación de las personas privadas de la libertad. Según Informe del Comité Contra la Tortura (2007, p. 169), se destacan:

- Las administrativas: traslados compulsivos sin cuida-
do en la continuación de las trayectorias educativas, los
procedimientos internos de acceso a la escuela y la docu-
mentación solicitada para el ingreso a distintos niveles
educativos.
- La aplicación de los criterios de seguridad interna: la ne-
cesidad de articular una convivencia reglada entre el Ser-
vicio Penitenciario y la Escuela, que supere las situaciones

Educação \& Realidade, Porto Alegre, v. 38, n. 1, p. 71-92, jan./mar. 2013. 73

Disponível em: <http://www.ufrgs.br/edu_realidade> 
tensas en lo cotidiano, ya sea por la utilización del espacio como por la organización de los tiempos.

- Las económicas: la necesidad de una provisión sostenida de recursos financieros, de materiales didácticos y tecnológicos. También es necesario conocer el presupuesto destinado a la educación en cárceles.

- La infraestructura: la necesidad de observar el estado general de los edificios destinados a la educación, su diseño, utilización y mantenimiento. Los espacios de la escuela suelen estar compartidos, otras veces limitados en tamaño, lo que ocasiona el no acceso de manera cotidiana de muchas personas detenidas.

- La superposición de ofertas educativas: en muchas unidades penales conviven a la vez un programa de alfabetización - de carácter temporal - con la educación básica formal - de carácter progresivo -; dicha situación suele desconcertar a los alumnos cuando se exige optar por una de ellas, cuando en realidad son los programas de alfabetización los que refuerzan la educación básica y por ende no son opciones que se descartan sino sistemas que se refuerzan entre sí. Se recuerda que la educación formal es el componente sustantivo del derecho a la educación.

- La Formación Profesional: la necesidad que la oferta de formación profesional tenga una real y sustantiva articulación con las exigencias del post-carcelario y la comunidad extramuros.

- Una necesaria sistematicidad en la elaboración de documentos específicos de asistencia técnica - pedagógica basados en la investigación, dirigidos a los trabajadores/ as de la educación, por parte de las agencias estatales responsables de la educación pública en las cárceles.

- Una necesaria formación docente específica en Derechos Humanos para todos los niveles educativos, implementada de manera sistemática parte del Estado, vinculada al contexto de la privación de la libertad.

- La necesidad de fortalecer los mecanismos de designación del personal docente, directivo y de supervisión en la educación formal en las cárceles, acercándolo a la legalidad establecida por la educación oficial y común que potencie una educación en las cárceles más pública y democrática y por ende, estas características repercutan en una cárcel abierta que genere un espacio de comunicación con el afuera.

- La necesidad de fortalecimiento y ampliación de la educación terciaria universitaria y no universitaria. Se aprecian acciones de extensión por parte de las universidades, pero aún no se evidencian, a partir de los convenios acordados, un crecimiento de la oferta de carreras, de la matricula y de un programa real y concreto por parte de las universidades que manifieste que la cárcel es un espacio social concreto en su agenda pública. 
La situación actual de las cárceles en general, independientemente de los avances favorables en educación, y por la cual nuestro país se encuentra observado por la comunidad internacional ${ }^{4}$, constituye el contexto cotidiano de dicha acción educativa. Dadas las restricciones antes mencionadas, esto genera condiciones desfavorables aunque no imposibles de superar si es que la decisión política, educativa y penitenciaria confluyen en tanto perspectiva y acción en favor de la educación como un derecho humano ${ }^{5}$.

En relación con lo anterior, se rescata el análisis llevado adelante por CIPPEC (Centro de Implementación de Políticas Públicas para la Equidad y el Crecimiento) de Argentina en el cual se menciona la existencia de concepciones disciplinarias no acordes con los principios del derecho anulando de esta manera a los/as privados/as de su libertad en tanto sujetos de derechos. Así también, Rivas (2007, p.124) desde un punto de vista académico caracteriza a las escuelas en contexto de encierro como escuelas totales.

Una cuestión silenciada y poco estudiada en la Argentina es la existencia y permanencia de instituciones educativas con características cerradas, que pueden ser denominadas "escuelas totales". Nos referimos a algunas variantes de la educación en cárceles, institutos de menores, internados, en las fuerzas armadas y la policía.

En muchos de estos casos priman concepciones disciplinarias no acordes con varios de los principios del derecho a la educación defendidos en este libro.

Algunas de las vulneraciones más corrientes de los derechos que manifiestan estas instituciones son las siguientes:

- Desaparece la figura del alumno como sujeto de derechos, ganando terreno una concepción de autoridad en manos de la jerarquía institucional, que impone las reglas y los premios y castigos.

- Los procesos educativos no se basan en el respeto de los Derechos Humanos ni fomentan principios de organización y participación democrática.

- Entre los contenidos curriculares no se privilegia un abordaje de los principios de ciudadanía y de defensa de los Derechos Humanos.

- No se respetan las libertades individuales, sino que se priorizan los códigos internos férreos y disciplinarios, que coartan las posibilidades de expresión de los sujetos. - Todavía en muchas instituciones se recurre a castigos físicos y tratos humillantes, contrarios a cualquier doctrina del derecho moderno.

Cabe realizar estudios en profundidad para conocer mejor estos casos, y resulta injusto generalizar sin mayores evidencias empíricas que los conocimientos asistemáticos de referencia sobre estas instituciones. A su vez, es interesante el proceso de reforma que en algunas de estas instituciones se ha iniciado en años recientes, como por

Educação \& Realidade, Porto Alegre, v. 38, n. 1, p. 71-92, jan./mar. 2013.

Disponível em: <http://www.ufrgs.br/edu_realidade> 
ejemplo en parte de la educación carcelaria y en el área del Ministerio de Defensa con un reciente proyecto de transformación educativa.

Teniendo en cuenta el contexto específico de la cárcel, como institución cerrada y espacio social proclive a violaciones de los DDHH de manera continua

Sólo puede hablarse de la educación en el medio penitenciario si se parte de las dificultades estructurales que supone la definición de la cárcel como estructura de violencia y mecanismo de aislamiento social. El desarrollo educativo del individuo se refiere a su crecimiento en el plano social, laboral e intelectual... (Arnanz Vilalta, 1995, p. 65).

La cárcel, como ámbito de punición, jurídico, social y cultural absorbente y total de la privación de la libertad ambulatoria, suele convertirse en un ámbito tendiente a generar continuas violaciones a los DDHH (torturas, tratos crueles y degradantes, no acceso a derechos como la justicia, la salud, el trabajo, la educación, la cultura, la alimentación, entre los más destacados), que sumado a la situación de vulnerabilidad en la que han vivido las personas encarceladas y la profundización de esta situación por el impacto del encierro, hace a la cárcel un contexto singular y específico, sobretodo, a la hora de pensar y ejecutar políticas educativas; las cuales debieran estar observadas desde los organismos de DDHH (tanto del Estado como de la sociedad civil) en función de prevenir y reparar las sistemáticas violaciones a los DDHH que allí suceden.

A modo de tener un panorama más realista acerca de la población carcelaria, se presentan los siguientes datos estadísticos informados por el Programa de Educación en Contexto de Encierro sobre el año $2007^{6}$.

- $58 \%$ procesados (esperando juicio o sin condena firme)

- $69 \%$ entre 18 y 34 años

- $94 \%$ son varones

- $94 \%$ argentinos

- $71 \%$ solteros

- $6 \%$ sin ningún tipo de estudios

- $23 \%$ primario incompleto

- $47 \%$ primario completo

- $14 \%$ secundario incompleto

- $5 \%$ secundario completo

- $2 \%$ nivel superior completo o incompleto

- 80\% desocupados o con situación laboral precaria.

- $64 \%$ sin oficio o profesión al ser detenido

- $46 \%$ desocupado al ser detenido

- $89 \%$ residía en zonas urbanas (50\% en la provincia de Bs. As.)

- $82 \%$ se aloja en unidades penitenciarias provinciales

- 83\% no participó de programas de capacitación laboral 
en último año.

- $62 \%$ no participó en programas educativos en el último

año.

- 56\% sin trabajo renumerado en la cárcel

- 185 niños menores de 4 años viven con sus madres detenidas.

- $39 \%$ encarcelado por robo y tentativa de robo.

- $70 \%$ en condición de encierro por primer delito $(30 \%$ de reincidencia)

- $10 \%$ condenados a reclusión perpetua

\section{Estado Normativo Nacional Referido al Derecho a la Educación en Cárceles}

\section{El derecho a la educación en la cárcel, conceptualización}

La educación es un derecho que hace a la condición del ser humano, ya que a partir de ella se [...] construye el lazo de pertenencia a la sociedad, a la palabra, a la tradición, al lenguaje, en definitiva a la transmisión y recreación de la cultura, esencial para la condición humana (Núñez ,1999, p. 5). Por lo tanto, quien no recibe o no hace uso de este derecho pierde la oportunidad de pertenecer plenamente a la sociedad, a participar de manera real y constituirse en un ciudadano/a, que haga uso de sus derechos y cumpla con sus deberes a favor del desarrollo de la sociedad.

Es sabido que aquellas personas que por su situación de partida en la dinámica social se encuentran desfavorecidas no pudiendo gozar ni acceder a derechos como la educación, la salud, el trabajo, la vivienda, la cultura, pierden la posibilidad cierta de constituirse como seres humanos dignos. Dicha situación de vulnerabilidad social de estos grupos, los constituye como seres proclives a la condena de la exclusión, la marginalidad, la violencia, la desocupación y otras penurias.

Es por esta misma situación de vulnerabilidad, que la reclusión en establecimientos penales opera muchas veces como un depósito de aquellos hombres y mujeres, que por haber cometido un delito o por su condición de pobre, enfermo de SIDA, 'negro', 'villero'? , se los 'corre de la vista' de los demás integrantes de la sociedad. Lo mismo ocurrió en otras épocas con los/as locos/as, los/as leprosos/as, los homosexuales.

El caso de las personas detenidas en establecimientos penales es una muestra de vulnerabilidad social y de exclusión: son sujetos 'que no le sirven' a la sociedad ${ }^{8}$.

La garantía, por ejemplo, del acceso a la educación en los establecimientos penales, actúa como garantía de la condición de ser humano para aquellas personas que alguna vez han delinquido y una posibilidad cierta de "reducción de su vulnerabilidad social" (Zaffaroni, 1991) que a partir del encierro se profundiza mucho más.

Educação \& Realidade, Porto Alegre, v. 38, n. 1, p. 71-92, jan./mar. 2013.

Disponível em: <http://www.ufrgs.br/edu_realidade> 
Recordemos que la intención de la pena en la cárcel es la privación de la libertad. Por lo tanto, puede debatirse que el encarcelamiento, aunque se considere un castigo justificado, no debe llevar consigo una privación adicional de los otros derechos, ya que el único derecho que se priva, al estar detenido, es la libertad ambulatoria (CONFINTEA, 1997).

Pero muchas veces también significa la violación y privación del disfrute de los DDHH, incluyendo el derecho a la educación y el acceso a la cultura. Simultáneamente, los pocos intentos formales de vigencia de los DDHH en las cárceles (por ejemplo, la presencia de escuelas públicas en tanto instituciones que tienen la responsabilidad del disfrute de la educación) no son abastecidos debida y apropiadamente, siendo muchas veces actividades dirigidas para satisfacer la distracción, ocupación del tiempo libre pero no como indispensables para las personas privadas de la libertad que por definición no tienen posibilidad de acceso, por ejemplo, a actividades culturales como un teatro o un cine, un acceso directo y fluido a bibliotecas y actividades recreativas, y así poder disfrutar de estos derechos ${ }^{9}$.

Se dice entonces que les corresponde a las personas privadas de su libertad el goce, el ejercicio real de todos los derechos y garantías que imponen las leyes nacionales y provinciales, las leyes fundamentales, como la Constitución Nacional y Provincial y las supranacionales, tratados internacionales de DDHH ratificados por la Argentina.

Asimismo, en la gran mayoría de los instrumentos internacionales y nacionales, existen apartados dedicados a las personas privadas de la libertad, de donde se desprenden las leyes nacionales y provinciales para la aplicación a este grupo de la sociedad. En ellas se puede apreciar un tratamiento de cuestiones tales como condiciones de detención, acceso a la justicia, tiempos para el dictado de sentencia, la prevención de acciones como maltratatos, torturas, trabajo forzado, función de la cárcel, derechos y garantías de detenidos, procesados y penados, para niños/as en edad de privación de libertad, para el caso de las mujeres embarazadas, entre otros puntos.

Esto último se puede observar también en resoluciones o recomendaciones de organismos como por ejemplo los de las Naciones Unidas para esta población en particular. Las mismas son consideradas como guía de buena práctica para el modo en que el Estado conduce sus cárceles sin violar ningún derecho humano o por lo menos tratando de no hacerlo. Dichas obligaciones positivas y negativas de los Estados relacionadas con la efectividad de todos los derechos consagrados en los instrumentos se podrían centralizar de la siguiente manera: obligación de respetar, proteger y realizar. 


\title{
Normativa nacional sobre el Derecho a la Educación en el ámbito penitenciario
}

En el ámbito nacional, la República Argentina tiene incorporados en la Constitución Nacional, en su artículo 75 inciso 22, los tratados internacionales de derechos humanos, otorgándoles de esta manera, el máximo rango del que puede gozar una norma, es decir, que gozan de jerarquía constitucional. Además, en el texto de la Constitución Nacional, se adiciona la idea de "las condiciones de su vigencia", lo que implica que las resoluciones, observaciones de los distintos organismos que se desprenden de cada instrumento internacional tienen valor normativo, esto significa la obligación del Estado a la hora de garantizar y efectivizar el derecho.

Los distintos instrumentos señalados más arriba definen claramente el derecho a la educación en general, el tratamiento de la privación de la libertad y el desarrollo del derecho a la educación en privación de libertad.

Resulta indispensable, además, señalar que en el ámbito nacional hay dos leyes más que tienen que ser consideradas en lo referente a educación en cárceles: la Ley 26.206 de Educación Nacional ${ }^{10}$ y la Ley 24.660 de Ejecución de la Pena Privativa de la Libertad ${ }^{11}$.

La primera de estas leyes señala en el apartado de Principios, Derechos y Garantías lo siguiente:

\begin{abstract}
ARTICULO $4^{\circ}$ - El Estado nacional, las provincias y la Ciudad Autónoma de Buenos Aires tienen la responsabilidad principal e indelegable de proveer una educación integral, permanente y de calidad para todos/as los/as habitantes de la Nación, garantizando la igualdad, gratuidad y equidad en el ejercicio de este derecho, con la participación de las organizaciones sociales y las familias.

ARTICULO $8^{\circ}$ - La educación brindará las oportunidades necesarias para desarrollar y fortalecer la formación integral de las personas a lo largo de toda la vida y promover en cada educando/a la capacidad de definir su proyecto de vida, basado en los valores de libertad, paz, solidaridad, igualdad, respeto a la diversidad, justicia, responsabilidad y bien común...
\end{abstract}

En cuanto a Fines y Objetivos de la Política Educativa Nacional, se destacan en el Artículo 11 de la ley los siguientes incisos:

a) Asegurar una educación de calidad con igualdad de oportunidades y posibilidades, sin desequilibrios regionales ni inequidades sociales.

b) Garantizar una educación integral que desarrolle todas las dimensiones de la persona y habilite tanto para el desempeño social y laboral, como para el acceso a estudios superiores. 
c) Brindar una formación ciudadana comprometida con los valores éticos y democráticos de participación, libertad, solidaridad, resolución pacífica de conflictos, respeto a los derechos humanos, responsabilidad, honestidad, valoración y preservación del patrimonio natural y cultural. d) Garantizar la inclusión educativa a través de políticas universales y de estrategias pedagógicas y de asignación de recursos que otorguen prioridad a los sectores más desfavorecidos de la sociedad.

e) Asegurar condiciones de igualdad, respetando las diferencias entre las personas sin admitir discriminación de género ni de ningún otro tipo.

f) Garantizar a todos/as el acceso y las condiciones para la permanencia y el egreso de los diferentes niveles del sistema educativo, asegurando la gratuidad de los servicios de gestión estatal, en todos los niveles y modalidades.

g) Desarrollar las capacidades y ofrecer oportunidades de estudio y aprendizaje necesarias para la educación a lo largo de toda la vida.

h) Promover el aprendizaje de saberes científicos fundamentales para comprender y participar reflexivamente en la sociedad contemporánea.

k) Promover en todos los niveles educativos y modalidades la comprensión del concepto de eliminación de todas las formas de discriminación.

En referencia a la educación de adultos, la Ley de Educación Nacional, en cuanto a objetivos y criterios, establece lo siguiente:

ARTICULO 48. - La organización curricular e institucional de la Educación Permanente de Jóvenes y Adultos responderá a los siguientes objetivos y criterios:

a) Brindar una formación básica que permita adquirir conocimientos a desarrollar las capacidades de expresión, comunicación, relación interpersonal y de construcción del conocimiento, atendiendo las particularidades socioculturales, laborales, contextuales y personales de la población destinataria.

b) Desarrollar la capacidad de participación en la vida social, cultural, política y económica y hacer efectivo su derecho a la ciudadanía democrática.

c) Mejorar su formación profesional y/o adquirir una preparación que facilite su inserción laboral.

d) Incorporar en sus enfoques y contenidos básicos la equidad de género y la diversidad cultural.

e) Promover la inclusión de los/as adultos/as mayores y de las personas con discapacidades, temporales o permanentes.

Además y como cuestión especialísima existe un apartado destinado a la Educación en Contextos de Privación de Libertad ${ }^{12}$ a saber: 
ARTICULO 55. - La Educación en Contextos de Privación de Libertad es la modalidad del sistema educativo destinada a garantizar el derecho a la educación de todas las personas privadas de libertad, para promover su formación integral y desarrollo pleno. El ejercicio de este derecho no admite limitación ni discriminación alguna vinculada a la situación de encierro, y será puesto en conocimiento de todas las personas privadas de libertad, en forma fehaciente, desde el momento de su ingreso a la institución.

ARTICULO 56. - Son objetivos de esta modalidad:

a) Garantizar el cumplimiento de la escolaridad obligatoria a todas las personas privadas de libertad dentro de las instituciones de encierro o fuera de ellas cuando las condiciones de detención lo permitieran.

b) Ofrecer formación técnico profesional, en todos los niveles y modalidades, a las personas privadas de libertad. c) Favorecer el acceso y permanencia en la Educación Superior y un sistema gratuito de educación a distancia.

d) Asegurar alternativas de educación no formal y apoyar las iniciativas educativas que formulen las personas privadas de libertad.

e) Desarrollar propuestas destinadas a estimular la creación artística y la participación en diferentes manifestaciones culturales, así como en actividades de educación física y deportiva.

f) Brindar información permanente sobre las ofertas educativas y culturales existentes.

g) Contribuir a la inclusión social de las personas privadas de libertad a través del acceso al sistema educativo y a la vida cultural.

ARTICULO 57. - Para asegurar la educación de todas las personas privadas de libertad el Ministerio de Educación, Ciencia y Tecnología acordará y coordinará acciones, estrategias y mecanismos necesarios con las autoridades nacionales y provinciales y de la Ciudad Autónoma de Buenos Aires, con institutos de educación superior y con universidades. Corresponde al Ministerio de Justicia y Derechos Humanos y sus equivalentes provinciales y de la Ciudad Autónoma de Buenos Aires, así como a los organismos responsables de las instituciones en que se encuentran niños/as y adolescentes privados de libertad, adoptar las disposiciones necesarias para el cumplimiento de lo establecido en el presente capítulo.

ARTICULO 58. - Los sistemas educativos jurisdiccionales ofrecerán atención educativa de nivel inicial destinada a los/as niños/as de CUARENTA Y CINCO (45) días a CUATRO (4) años de edad, nacidos/as y/o criados/as en estos contextos, a través de jardines maternales o de infantes, así como otras actividades educativas y recreativas dentro y fuera de las unidades penitenciarias.

ARTICULO 59. - Todos/as los/as niños/as y adolescentes que se encuentren privados de libertad en instituciones

Educação \& Realidade, Porto Alegre, v. 38, n. 1, p. 71-92, jan./mar. 2013.

Disponível em: <http://www.ufrgs.br/edu_realidade> 
de régimen cerrado según lo establecido por el artículo 19 de la Ley No 26.061, tendrán derecho al acceso, permanencia y tránsito en todos los niveles y modalidades del sistema educativo. Las formas de implementación de este derecho responderán a criterios de flexibilidad y calidad que aseguren resultados equivalentes a los de la educación común.

Lo expuesto anteriormente constituye un gran avance en cuanto a la obligación del Estado en promover, garantizar, respetar y realizar el Derecho a la Educación en las cárceles, siendo el responsable de generar políticas específicas e integrales que hagan al disfrute de este derecho.

Se destaca, finalmente, la apreciación en este articulado de cuestiones vinculadas a la misión, condiciones de ejecución y objetivos de esta modalidad educativa, su relación con otras modalidades educativas, su forma de desarrollarse en el ámbito de privación de libertad y la atención sobre los colectivos tales como niños/as alojados/as con sus madres y niños/as y adolescentes privados/as de su libertad.

Por su parte, la Ley 24.660 establece en su Capítulo VIII, artículos 133 a 142 las reglas a las que debe someterse el Servicio Penitenciario Federal en materia educativa. En su texto anterior a la reforma de los artículos mencionados en 2011, se destaca:

[...] se puede indicar que desde el ingreso del interno se asegurará el ejercicio de su derecho de aprender "adoptándose las medidas necesarias para mantener, fomentar y mejorar su educación e instrucción” (art.133).

El artículo 134, de dicha ley decía:

[Que la enseñanza en un establecimiento penitenciario deberá ser] formativa [...] procurando que el interno comprenda sus deberes y las normas que regulan la convivencia en sociedad.

En tanto, el Informe de la Procuración Penitenciaria de la Nación ${ }^{13}$ (2002) deja en evidencia, por un lado, la obligatoriedad que la educación pertenezca al sistema público de enseñanza, pero, además y en cuanto al acceso y a las condiciones del disfrute del derecho a la educación, que le corresponden tanto al condenado/a como al procesado/a.

[...] la Ley 24.660 establece de consumo con lo legislado en el plano internacional, que la enseñanza corresponderá al sistema de educación pública para que el interno, a su egreso pueda continuar sus estudios sin inconvenientes, que la administración debe fomentar el interés del interno por el estudio, brindándole la posibilidad de acceder a servicios educativos en los distintos niveles del sistema y que todo establecimiento debe contar con una biblioteca (artículos 136, 137 y 140 respectivamente).

[...] Vale la aclaración que normas idénticas que las que 
regulan la educación de los condenados han sido insertas en los artículos 90 a 96 del Reglamento General de Procesados (Decreto 303/96), evitando con ello cualquier posibilidad de duda acerca de los derechos de los procesados respecto de la educación.

En el ámbito de la Provincia de Buenos Aires ocurre algo similar en cuanto a la normativa que define claramente el Derecho a la Educación en general, el tratamiento de la privación de libertad y el desarrollo del Derecho a la Educación en la privación de la libertad.

La Educación General Básica de Adultos, como también otros niveles y modalidades educativos, está a cargo de la Dirección General de Cultura y Educación y no del Servicio Penitenciario Bonaerense, lo cual implica una serie de interacciones institucionales en general tensionadas por ser instituciones (escuela y cárcel) con fines y responsabilidades, al menos en su definición social, diferentes.

\section{Reforma en la Ley de Ejecución Penal: avance histórico}

Ahora bien, a finales de julio 2011, fue aprobado el proyecto de ley sobre "Educación y estímulo en establecimientos penitenciarios"14, en cual se sustituyen del Capítulo VIII, los artículos 133 a 142, de la ley 24.660 .

En una primera valoración, se establece que todas las personas privadas de su libertad tienen derecho a la educación pública y es clave que cuando se hable de educación se hable de acceder a un derecho humano, esto implica adherir a principios tales como no discriminación, igual de oportunidades, equidad, calidad en lo que se refiere a su ejercicio y disfrute por parte de las personas privadas de la libertad. Además es destacable el rol del Estado en cuanto a su rol de respetar, proteger, garantizar, promover y facilitar el acceso y el disfrute con calidad de la educación.

Art. 133. Derecho a la educación

Todas las personas privadas de su libertad tienen derecho a la educación pública. El Estado nacional, las provincias y la Ciudad Autónoma de Buenos Aires tienen la responsabilidad indelegable de proveer prioritariamente a una educación integral, permanente y de calidad para todas las personas privadas de su libertad en sus jurisdicciones, garantizando la igualdad y gratuidad en el ejercicio de este derecho, con la participación de las organizaciones no gubernamentales y de las familias.

Se plasma, además, que la educación dentro de las unidades penales no debe diferir de la que se provee fuera de éstas en cuanto a que:

Los fines y objetivos de la política educativa respecto de las personas privadas de su libertad son idénticos a los 
fijados para todos los habitantes de la Nación por la Ley Nacional de Educación. Las finalidades propias de esta ley no pueden entenderse en el sentido de alterarlos en modo alguno. Todos los internos deben completar la escolaridad obligatoria fijada en la ley (Art. 133, 3º párrafo).

Otro punto destacado de esta iniciativa la señala el Artículo 135 en cuanto expresa de manera precisa que el acceso a la educación por parte de los alojados no tendrá limitación alguna, lo cual es un gran avance y potencia lo ya planteado en la Ley Nacional de Educación de 2006 en su articulado 55.

Art. 135 Restricciones prohibidas al derecho a la educación.

El acceso a la educación en todos sus niveles y modalidades no admitirá limitación alguna fundada en motivos discriminatorios, ni en la situación procesal de los internos, el tipo de establecimiento de detención, la modalidad de encierro, el nivel de seguridad, el grado de avance en la progresividad del régimen penitenciario, las calificaciones de conducta o concepto, ni en ninguna otra circunstancia que implique una restricción injustificada del derecho a la educación.

En cuanto al artículo 136, Situaciones especiales, de su redacción se desprende que se omite incluir muchas otras situaciones especiales. Por ejemplo, el tema de mujeres, ya que no sólo se dificulta la educación para aquellas que están embarazadas, más allá de que deban hacer algún reposo en particular, ya que también están quienes tienen hijos y no pueden ir a la escuela porque algunos/as docentes no las dejan concurrir con sus hijos.

Art. 136 Situaciones especiales.

Las necesidades especiales de cualquier persona o grupo serán atendidas, a fin de garantizar el pleno acceso a la educación.

La mujer privada de su libertad será especialmente asistida durante el embarazo, el parto y se le proveerán los medios materiales para la crianza adecuada de su hijo mientras éste permanezca en el medio carcelario, facilitándose la continuidad y la finalización de sus estudios. Todos los niños y adolescentes que se encuentren privados de su libertad en instituciones de régimen cerrado, tendrán derecho al acceso, permanencia y tránsito en todos los niveles y modalidades del sistema educativo.

Las formas de implementación de esta derecho responderán a criterios de flexibilidad y calidad que aseguren resultados equivalentes a los de la educación común

Se destaca, además, el Artículo 137, el cual pone en cabeza de la gestión penitenciara, la obligación de la "notificación al interno" del contenido de este capítulo de la ley en lo referente al acceso a la educa- 
ción, alcanzando así no solo el conocimiento de esta ley sino también la exigibilidad de este derecho. Asimismo, sería importante también promocionarse además las instancias educativas formales y las propuestas no formales existentes.

El contenido de este capítulo será puesto en conocimiento de todas las personas privadas de libertad, en forma fehaciente, al momento de su ingreso a una institución. Desde el momento mismo del ingreso se asegurará al interno su derecho a la educación, y se adoptarán las medidas necesarias para mantener, fomentar y mejorar sus capacidades e instrucción. Cada vez que un interno ingrese a un establecimiento, las autoridades educativas y penitenciarias deberán certificar su nivel de instrucción dejando constancia en el legajo personal y en los registros pertinentes.

En lo que describe a las "Acciones de implementación” se subraya a favor de la accesibilidad y disponibilidad de la educación, que los ministerios involucrados (de Educación y de Justicia) deben asumir compromisos de diversa índole, lo cual no solo fomenta la formalización de acuerdos y convenios entre las partes, sino también pone en palabras funciones y responsabilidades concretas exigibles a la hora de llevar adelante acciones de monitoreo, como así también a la hora de formular indicadores de realización de este derecho.

\section{Art. 138. Acciones de implementación}

El Ministerio de Educación acordará y coordinará todas las acciones, estrategias y mecanismos necesarios para la adecuada satisfacción de las obligaciones de este capítulo con las autoridades nacionales y provinciales y de la Ciudad Autónoma de Buenos Aires, con Institutos de educación superior de gestión estatal y con Universidades Nacionales.

El Ministerio de Justicia, Seguridad y Derechos Humanos y sus equivalentes provinciales y de la Ciudad Autónoma de Buenos Aires, la autoridad penitenciaria, y los organismos responsables de las instituciones en que se encuentran niños y adolescentes privados de su libertad, deberán atender las indicaciones de la autoridad educativa y adoptar todas las medidas necesarias para el cumplimiento de lo establecido en el presente capítulo.

Entre otras acciones, deberán proveer de ámbitos apropiados para la educación, tanto para los internos como para el personal docente y penitenciario, adoptar las previsiones presupuestarias y reglamentarias pertinentes, remover todo obstáculo que limite los derechos de las personas con discapacidad, asegurar la permanencia de los internos en aquellos establecimientos donde cursan con regularidad, mantener un adecuado registro de los créditos y logros educativos, requerir y conservar cual-

Educação \& Realidade, Porto Alegre, v. 38, n. 1, p. 71-92, jan./mar. 2013. 
quier antecedente útil a la mejor formación del interno, garantizar la capacitación permanente del personal penitenciario en las áreas pertinentes, fomentar la suscripción de convenios de cooperación con instituciones públicas y privadas.

En cuanto a la documentación y certificación y, favoreciendo a la continuidad y a una trayectoria educativa provechosa de la persona en privación de su libertad, se establece que:

Art. 139. Documentación y certificados

A los efectos de garantizar la provisión y la continuidad de los estudios, se documentará en el legajo personal del interno o procesado los créditos y logros educativos correspondientes alcanzados de manera total o parcial que, además, se consignarán en la documentación de la institución educativa correspondiente. En caso de traslado del interno o procesado, la autoridad educativa deberá ser informada por la autoridad judicial correspondiente para proceder a tramitar de manera automática el pase y las equivalencias de acuerdo a la institución educativa y al plan de estudios que se corresponda con el nuevo destino.

Como algo novedoso de esta ley, se presenta lo contenido en el artículo 140, "estímulo educativo", el cual consiste en reducir los tiempos de acceso a la culminación de las diferentes fases y períodos de la progresividad de la pena. Esto favorece el alcance, con mayor rapidez, de figuras procesales como la libertad asistida o condicional entre otras. Los plazos establecidos en la ley son los siguientes: por culminar un ciclo lectivo anual, la reducción es de 1 mes; en caso de terminar el nivel primario o culminar un curso de formación profesional anual, la reducción es de 2 meses; por estudios secundarios o terciarios la reducción es de 3 meses; por estudios de nivel universitario es de 4 meses; y en el caso de cursos de postgrados es de 2 meses. Estos plazos, serán acumulativos hasta un máximo de 20 meses.

Por último, la ley presenta dos articulados vinculados con el 'control' que involucra tanto a los Ministerios de Educación y Justicia, como al Poder Judicial.

En cuanto al control de la gestión educativa de las personas privadas de su libertad, el Artículo 141 señala:

El Ministerio de Educación y el Ministerio de Justicia, Seguridad y Derechos Humanos y sus equivalentes provinciales deberán establecer, en el marco del Consejo Federal de Educación, un sistema de información público, confiable, accesible y actual, sobre la demanda y oferta educativa, los espacios y los programas de estudio existentes en cada establecimiento y mantener un adecuado registro de sus variaciones. Deberá garantizarse el amplio acceso a dicha información a la Procuración Penitenciaria de la 
Nación, a organizaciones no gubernamentales interesadas en el tema, y a abogados, funcionarios competentes, académicos, familiares de las personas privadas de su libertad, y a toda otra persona con legítimo interés.

Esto resulta muy importante ya que permite contar con información necesaria para evaluar los avances y retrocesos del disfrute de la educación en el contexto de la cárcel. Información cuyo acceso no se restringe a los organismos estatales, quedando, a su vez, disponible para la sociedad civil, comprometiendo, de esta manera a dicho actor social en la problemática.

El Artículo 142, plantea el Control Judicial de este derecho, que de por sí favorece a la exigibilidad y a la judicialización ante la presencia de obstáculos e incumplimientos en el acceso a la educación, promoviendo la competencia del Poder Judicial bajo la vía del hábeas corpus correctivo y de forma colectiva.

Este tipo de mecanismos judiciales, se utilizan frecuentemente para reclamar los agravamientos en las condiciones de detención de las personas privadas de su libertad. Así llegó a la justicia, el emblemático fallo "Verbitsky, Horacio s/habeas corpus", mediante el cual el máximo Tribunal de la Nación, la Corte Suprema de Justicia, fijó los estándares de protección de los derechos de los detenidos que los distintos poderes provinciales deben respetar para cumplir con el mandato de la Constitución Nacional y con los pactos internacionales de derechos humanos que, como ya mencionamos, tienen jerarquía constitucional. También ordenó a la justicia provincial verificar y remediar las condiciones inhumanas de detención de los presos detenidos a su disposición, así como disponer la inmediata libertad de los adolescentes y enfermos detenidos en comisarías.

Esto es, sin duda, un gran avance en términos de garantía, protección y respeto al derecho. Por un lado, obliga a que los organismos de control y monitoreo de cárceles como así también la sociedad civil, se comprometan aun más en convertir en realidad el disfrute de este derecho. Por otro, conlleva a determinar, de alguna manera, cuáles serían aquellos indicadores que permitan dar cuenta si este derecho está siendo garantizado, respetado y protegido en términos de la normativa vigente.

El Grupo de Estudio de Educación en Cárceles (GESEC), tuvo oportunidad de efectuar sus valoraciones respecto al Proyecto de Ley presentado por la Diputada Dra. Adriana Puiggrós, por el cual se modificó el capítulo VIII de la ley 24.660 - Régimen de Ejecución de la Pena Privativa de la Libertad - en materia de Educación en Establecimientos Penitenciarios. Dicho proyecto de ley, se receptó con alto grado de satisfacción, en virtud del interés y la propuesta de normativa efectuada, sobre la educación en el ámbito de la cárcel, ya que desde su creación en el año 2002, el GESEC viene promoviendo este tipo de iniciativas que

Educação \& Realidade, Porto Alegre, v. 38, n. 1, p. 71-92, jan./mar. 2013.

Disponível em: <http://www.ufrgs.br/edu_realidade> 
hacen al fortalecimiento del ejercicio pleno del derecho humano a la educación en la privación de la libertad.

\section{Conclusiones}

Ante todo lo expuesto, lo primero que se concluye es la oportunidad social que genera la educación, que al ser un derecho efectivamente garantizado aumenta el disfrute de todos los derechos y libertades individuales y cuando se niega o viola ese derecho, priva a las poblaciones del disfrute de muchos derechos y libertades. Además, se considera a la educación como una oportunidad social tanto para el presente como para el futuro, ya que permite a la persona encarcelada desarrollar trayectorias educativas provechosas, concretando el derecho humano en un proyecto de vida.

De esta manera la educación en tanto derecho es inherente a la persona y a la vez, opera como un derecho llave, ya que su realización y goce 'abre' el conocimiento y ejercicio de otros derechos.

En este sentido se dice, además, que la educación, en tanto derecho llave, permite al detenido 'defenderse de la cárcel'15 (Caamaño, 2006) morigerar los efectos nocivos del encierro, o bien pensarse distinto o con un destino diferente.

Al respecto, el goce pleno del Derecho a la Educación es una manera de eliminar las desigualdades destinadas a perpetuarse en el contexto del encierro. Por otro lado y para que la educación no sea la que genere la desigualdad, están las disposiciones internacionales en materia de DDHH que otorgan prioridad a la eliminación de las desigualdades como meta clave de la educación.

Sumado a esto, hay un claro reconocimiento de que la educación es un instrumento esencial para el desarrollo personal y la participación en la sociedad, en la medida en que satisfaga las necesidades educativas de los sujetos de la acción educativa y se constituya como una garantía real de los DDHH de las personas privadas de su libertad.

De esta forma, la educación repercute en la oferta y oportunidad real de las personas en reducir la situación de vulnerabilidad social, cultural y psicológica que, de alguna manera, las han llevado a cometer una trasgresión a la ley.

Respecto al vocabulario expresado en la normativa vigente, al uso de la palabra 'interno' al denominar la persona privada de libertad, creemos que, amén que la ley de ejecución lo denomina así, es dable dar otro tipo de denominación, ya que la utilización de la denominación interno cuando hablamos de la persona privada de libertad se refiere a internado, donde se desprende una mirada más hospitalaria, biologicista y por ende de alguien que está sufriendo una internación por motivos de no contar con una salud plena. Es decir, de trasfondo, al decir inter- 
no, estamos diciendo en esta perspectiva que la persona encarcelada es alguien enfermo y en verdad es una persona presa, detenida, privada de su libertad, encarcelada, hasta enjaulada si se permite.

Asimismo, entendemos que respecto a otros colectivos de personas, debería especificarse en la normativa, cuando se refiere a que no importará su condición procesal, o su causa, y en este sentido, se podría decir algo como que se arbitrarán los medios y recursos para garantizar la educación de personas que por su causa o resguardo no pueden concurrir a la escuela junto a otros grupos o personas. En este sentido, será una gran oportunidad para poner en debate experiencias como por ejemplo, las que prevén poner una reja entre docente y alumno. Esto debe ser considerado inaceptable.

En igual sentido se debe profundizar el debate sobre tema del castigo cuando interfiere con el derecho, esto es en cuanto a la proporcionalidad, la racionalidad y la legalidad de la medida de sanción y el ejercicio del derecho. En el caso de personas con discapacidades también deberá garantizarse y ponerse atención en los mecanismos para que esto ocurra.

Para los colectivos llamados de 'extrema peligrosidad' también se deberán arbitrar los medios para que éstos puedan participar del proceso educativo como debe ser, en forma personal. Esto implica no sólo recursos físicos, sino también tener en cuenta los derechos de los docentes como trabajadores, es decir que, o bien se deben designar nuevos cargos, o si se decide aplicar esta forma de "educación a distancia", deberán contemplarse honorarios para los docentes por esta tarea. Obviamente, somos conscientes que todos estos aportes y cambios implican una decisión política que conlleva una nueva distribución de recursos económicos.

Por otro lado, el tratamiento normativo de la educación en privación de libertad, ya sea en las leyes vinculadas a la ejecución de la pena como en aquellas vinculadas a la educación, constituyen el sustento de políticas educativas y penitenciarias que puedan garantizar la realización del derecho. A su vez, se presenta como la obligación estatal en universalizar su disfrute. Ahora bien, la ley de ejecución de la pena privativa de la libertad, establece que los detenidos deben completar su escolaridad obligatoria. Aquí es dable reconocer el valor de la autonomía de la persona adulta en cuanto a armar su destino o proyecto de vida. El Estado, como más arriba se señaló, debe garantizar el acceso, no obligar al disfrute de un derecho ya que es responsabilidad y decisión de cada sujeto qué hacer con su vida más allá de todas las restricciones que impele la vida en la cárcel. Es decir, el docente podrá o deberá motivar al detenido para que complete su escolaridad, más que planteárselo como un deber.

Pues la garantía del Derecho a la Educación de las personas privadas de libertad bajo criterios de calidad de realización, es un esfuerzo concreto en pos de una política pública de seguridad basada en el

Educação \& Realidade, Porto Alegre, v. 38, n. 1, p. 71-92, jan./mar. 2013. 
respeto a la dignidad de la persona, a la justicia, a la democracia y los $\mathrm{DDHH}^{16}$; que de seguro favorecerá a la búsqueda incansable de tener cárceles más humanas, más democráticas, más públicas.

Así darle impulso a la educación en las cárceles es un requisito para el éxito en la vuelta a la vida libre y en la futura inclusión social de los/as detenidos/as, como así también es una contribución al desarrollo real y sostenible de la sociedad que la pone en práctica.

Recebido em 16 de julho de 2012 Aprovado em 18 de dezembro de 2012

\section{Notas}

1 Se suma a estas reformas normativas, las actuadas en los artículos 133 a 142 de la Ley Nacional 24.660 (Ley de Ejecución Penal). Los mencionados artículos tratan de manera específica el tema educativo para las personas privadas de la libertad.

2 Para el caso de Argentina ver Informe Anual de la Procuración Penitenciaria Federal 2003-2005 (2006); Programa Nacional Educación en establecimientos Penitenciarios y de Minoridad (2004); Informe del Comité Contra la Tortura (2007).

3 Recomendación No. R (89) 12 del Consejo de Europa, Comité de Ministros de los estados miembros sobre educación en prisiones, Adoptada por el Comité de Ministros el 13 de Octubre de 1989 en el 429 encuentro de Ministros Diputados. Ver: <www.redlece.org $>-$ Red latinoamericana de educación en contextos de encierro.

4 El Comité Contra la Tortura y Otros Tratos o Penas Crueles Inhumanos y Degradantes de Naciones Unidas dictó sus Conclusiones y Recomendaciones, respecto del caso argentino para el año 2004. Ver: <http://www.acnur.org/biblioteca/ pdf/3369.pdf $>$. Se menciona, además, el caso de 35 muertos del penal de Varones de Santiago del Estero, en noviembre de 2007. Ver: <http://www.cronista. com/notas/115933-son-39-las-victimas-fatales-el-motin-santiago-del-estero>.

5 Tal como sostiene Tomasevski, K. (2003): “...es altamente improbable reparar el desequilibrio existente en las oportunidades de vida y de participación en la sociedad sin el previo reconocimiento del derecho a la educación".

6 Ministerio de Justicia Argentina, Sneep, 2007. Datos recogidos en: <http://www. mcye.gov.ar/curriform/publica/ed_pen>.

7 Villero: en Argentina se denomina así a las personas que viven en villas, asentamientos con poco o nulo acceso a servicios básicos, similares a las favelas de Brasil.

8 El sociólogo francés, Löic Wacquant (1999) se refiere a una criminalización de la pobreza, cuando a los pobres se los encierra por pobres, siendo estos, producto del propio sistema.

9 Imaginemos el impacto en la privación de la libertad de la educación y la cultura, cuánto más se constituyan como derechos que hagan a la calidad de vida, al desarrollo del diálogo, a la resolución no violenta de conflictos, al desarrollo de la cultura de la paz y la no violencia, entre otras valoraciones.

10 Promulgada en diciembre de 2006. Ver texto competo en: <www.me.gov.ar>. 
11 Promulgada en julio de 1996. Ver texto completo en: <www.ppn.gov.ar>.

12 El Lic. Francisco Scarfó ha participado, con carácter de asesor, en representación de la Procuración Penitenciaria de la Nación, en los debates para la formulación de este articulado; convocado por el Programa de Educación en Contextos de Encierro del Ministerio de Educación, Ciencia y Técnica de la Nación durante el año 2006.

13 La Procuración Penitenciaria de la Nación es un organismo oficial dependiente del Poder Legislativo, el objetivo fundamental de esta institución es proteger los derechos humanos de los internos comprendidos en el Régimen Penitenciario Federal de todas las personas privadas de su libertad.

14 Debe tenerse en cuenta que solamente podrá ser tenido por auténtico el texto publicado en el respectivo Trámite Parlamentario, editado por la Imprenta del Congreso de la Nación Argentina. Disponible en: <http://www.adrianapuiggros.com.ar/proyectos.php>.

15 Hace referencia a la resistencia que puede oponer la educación ante la situación de vulnerabilidad a la cual queda expuesta la persona encarcelada.

16 Conclusiones del Primer Congreso Nacional de Educación en las Cárceles Educar tras los muros - (2000).

\section{Referências}

ARGENTINA. $1^{\circ}$ CONGRESO NACIONAL DE EDUCACIÓN EN LAS CÁRCELES - Educar tras los muros. Conclusiones. Argentina: Univ. Del Centro, Olavarría, Prov. de Bs. As, Oct. 2000.

ARGENTINA. Comité Contra la Tortura. Informe anual sobre DDHH: El sistema de la Crueldad III. Argentina: Comisión Provincial por la Memoria Prov. De Bs. As, La Plata, 2007.

ARNANZ VILALTA, Enrique. Educar en la Prisión: la situación actual y futuros retos. Madrid: Federación Española de Universidades Populares, Resumen de Prensa, n. 89, abr. 1995.

CAAMAÑO, Cristina; GARCÍA, Darío. Manual Práctico para defenderse de la Cárcel. Buenos Aires: Instituto de Estudios Comparados en Ciencias Penales y Sociales (INECIP), 2006.

COLEYE, Andrew. La Administración Penitenciaria en el Contexto de los Derechos Humanos. Londres, Reino Unido: International Centre For Prisión Studies, 2002.

GOFFMAN, Erving. Internados. Ensayos sobre la situación social de los enfermos mentales. Buenos Aires: Amorrortu, 1994.

INTERNATIONAL Penal Reform. Manual de la Buena Práctica Penitenciaria. 2. ed (R332m), San José de Costa Rica, 2002.

NUÑEZ, Violeta. Pedagogía Social: cartas para navegar en el nuevo milenio. Argentina: Edit. Santillana, Bs. As, 1999.

PROCURACIÓN Penitenciaria Federal. Recomendación No 235 del Procurador Penitenciario Federal, Ciudad Autónoma de Buenos Aires, 24 abr. 2002.

RIVAS, Axel. El Desafío del Derecho a la Educación en Argentina: un dispositivo analítico para la Acción. Fundación CIPPEC, Buenos Aires, 2007. Disponível em: <www.cippec.org>. Acesso em: 01 fev. 2012.

Educação \& Realidade, Porto Alegre, v. 38, n. 1, p. 71-92, jan./mar. 2013. 
SCARFÓ, Francisco. El Derecho a la educación en las cárceles como garantía de una Educación en Derechos Humanos. Revista del Instituto Interamericano de Derechos Humanos, San José de Costa Rica, n. 36, jul./dez. 2003.

SCARFÓ, Francisco José. El Derecho Humano a la Educación en las Cárceles: los fines de la educación básica en las cárceles en la Provincia de Buenos Aires. La Plata: Editorial Universitaria de La Plata, 2008.

TOMASEVSKI, Katerine. Contenido y vigencia del derecho a la educación. Cuadernos Pedagógicos, IIDH, San José de Costa Rica, 2003.

UNESCO. CONFITEA. Educación de adultos y reclusos, 5ta. Conferencia Internacional de Educación de Adultos. Hamburgo: UNESCO, 1997.

WACQUANT, Löic. Las Cárceles de la Miseria. Buenos Aires: Editorial Manantial, 2004.

ZAFFARONI, Eugenio. La Filosofía del sistema penitenciario contemporáneo. In: BELOFF, Mary Ana; BOVINO, Alberto; CURTIS, Christian (Org.). Cuadernos de la Cárcel, Edición especial de No hay derecho. Buenos Aires: Edit La Galera, 1991.

Francisco Scarfó é mestre em Direitos Humanos pela Universidade Nacional de La Plata, Argentina. Professor de Ciência da Educação. Assessor em Educação da Procuradoria Penitenciária da Nação. Consultor do Instituto Interamericano de Direitos Humanos (Costa Rica) e do Instituto Internacional de Direitos Humanos da Universidade De Paul de Chicago. Especialista em Educação para jovens e adultos em situação de privação de liberdade na Argentina. País: Argentina/ Buenos Aires.

Email: franciscoscarfo@speedy.com.ar

Florencia Pérez Lalli é licenciada em Comunicação Social, Presidenta do Grupo de Estudos sobre Educação em Espaços de Encarceramento (Gesec) da Argentina. Especialista em Educação para jovens e adultos em situação de privação de liberdade na Argentina. País: Argentina/ Buenos Aires. Email: florpl31@hotmail.com

Ivana Montserrat é advogada, assessora do Grupo de Estudos sobre Educação em Espaços de Encarceramento (Gesec) da Argentina. Auxiliar da Procuradoria Geral da SCJBA - Argentina. Especialista em Educação para jovens e adultos em situação de privação de liberdade na Argentina. País: Argentina.

Email: info@gesec.com.ar 